\title{
A retrospective controlled cohort study in 176 patients on the efficacy of SEAS exercises in AIS treatment: brace precriptions, and radiographic and clinical outcomes at the end of growth
}

\author{
Michele Romano*, Alessandra Negrini, Paolo Pizzetti, Stefano Negrini
}

From 7th International Conference on Conservative Management of Spinal Deformities Montreal, Canada. 20-22 May 2010

\section{Introduction}

SEAS exercises proved to reduce brace prescription and give radiographic and clinical results better than Usual Physiotherapy (UP) in the short-term, while at the end of growth only clinical and radiographic results in a little group of patients have been presented. Aim of this paper is to verify a complete set of outcome (brace prescription, radiographic and clinical results) at the end of growth in 176 patients.

\section{Material and methods}

Design: retrospective controlled cohort study in all patients from our Institute database who ended treatment between 2003 and 2009 due to brace prescription, or because they reached Risser 3 and/or 14 years of age for females and 15 for males. Inclusion criteria: AIS, prescription of exercises at first evaluation. Groups were self-chosen by patients: SEAS (78 patients) vs UP (98). SEAS is based on the Active Self-Correciton specific movement used in various exercises, aimed mainly at stabilization, postural control and balance; SEAS patients come to our Institute once every three months for 1.5 hours devoted to PT evaluation, change of exercises and counselling. UP included many different techniques proposed to patients by their own PT. All patients performed exercises two or three times a week per 45 to 60 minutes (no statistical differences between groups).

\section{Results}

We did not find differences between groups at brace prescription, while at start of treatment SEAS had worst ATR than UP, but similar Cobb degrees. Braces have been prescribed in $28 \%$ for SEAS and $43 \%$ for UP $(\mathrm{P}<0.05)$; brace hours prescribed in UP was higher than SEAS (19.7 vs $18.2-\mathrm{P}<0.05)$; braced patients had worst curves at start of treatment mainly in UP (particularly in thoracic curves); they also had bad compliance to SEAS treatment (exercises changed every 4.2 months vs $3.2-\mathrm{P}<0.05)$. At the end of treatment SEAS group had results better than UP for TRACE $(-2.2-\mathrm{p}<0.05)$ and ATR improvement $(-1.1-$ $\mathrm{p}<0.05)$.

\section{Discussion}

Exercises are useful for AIS; among the different techniques SEAS has proven its efficacy in the short and long term. This study also proves the importance of specific exercises (SEAS) instead of general ones (UP). Brace prescription should be carefully considered as a possible outcome for AIS patients treated with exercises during growth, since it is very relevant in a patient perspective. Obviously it can vary a lot among different physicians; nevertheless, we did not find differences between the groups at the moment of brace prescription, confirming the stability of this outcome in this specific study.

ISICO (Italian Scientific Spine Institute), Milan, Italy

Full list of author information is available at the end of the article 


\section{Conclusion}

SEAS allows to obtain results through exercises made "only" twice a week, and with treatment by an expert PT only once every three months, unlike any other PT technique. SEAS should carefully be considered to reduce costs and allow treatment of patients coming from places far away from the treating Centre (as it is usual for AIS).

Published: 10 September 2010

doi:10.1186/1748-7161-5-S1-O25

Cite this article as: Romano et al:: A retrospective controlled cohort study in 176 patients on the efficacy of SEAS exercises in AIS treatment: brace precriptions, and radiographic and clinical outcomes at the end of growth. Scoliosis 2010 5(Suppl 1):O25.

Submit your next manuscript to BioMed Central and take full advantage of:

- Convenient online submission

- Thorough peer review

- No space constraints or color figure charges

- Immediate publication on acceptance

- Inclusion in PubMed, CAS, Scopus and Google Scholar

- Research which is freely available for redistribution

Submit your manuscript at www.biomedcentral.com/submit 